\title{
Stefania Valeri, Libri nuovi scendon l'Alpi. Venti anni di relazioni franco-italiane negli archivi della Société typographique de Neuchâtel (1769-1789)
}

\section{Franco Piva}

\section{(2) OpenEdition \\ Journals}

Edizione digitale

URL: http://journals.openedition.org/studifrancesi/9545

DOI: $10.4000 /$ studifrancesi.9545

ISSN: 2421-5856

\section{Editore}

Rosenberg \& Sellier

\section{Edizione cartacea}

Data di pubblicazione: 1 décembre 2007

Paginazione: 658-659

ISSN: 0039-2944

\section{Notizia bibliografica digitale}

Franco Piva, «Stefania Valeri, Libri nuovi scendon I'Alpi. Venti anni di relazioni franco-italiane negli archivi della Société typographique de Neuchâtel (1769-1789)», Studi Francesi [Online], 153 (LI | III) | 2007, online dal 30 novembre 2015, consultato il 12 janvier 2021. URL: http://journals.openedition.org/ studifrancesi/9545; DOI: https://doi.org/10.4000/studifrancesi.9545

Questo documento è stato generato automaticamente il 12 janvier 2021.

\section{cc) $(9)$}

Studi Francesi è distribuita con Licenza Creative Commons Attribuzione - Non commerciale - Non opere derivate 4.0 Internazionale. 


\title{
Stefania Valeri, Libri nuovi scendon l'Alpi. Venti anni di relazioni franco- italiane negli archivi della Société typographique de Neuchâtel (1769-1789)
}

\author{
Franco Piva
}

\section{NOTIZIA}

STEFANIA VALERI, Libri nuovi scendon l'Alpi. Venti anni di relazioni franco-italiane negli archivi della Société typographique de Neuchâtel (1769-1789), Macerata, EUM, 2006, pp. 314.

1 Sono note da tempo le strette relazioni che legarono la cultura italiana alla cultura d'oltralpe; così come sono, grosso modo, noti i canali, più o meno clandestini, ai quali gli spiriti più aperti della cultura italiana si rivolgevano per saziare la loro sete di novità. Meno conosciuto, almeno ai non addetti ai lavori, è il ruolo che in quest'opera di diffusione della cultura francese svolse la Societé typographique de Neuchâtel, una stamperia-libreria sorta nel 1769 in una città che per la sua posizione geografica e politica godeva di uno status per molti versi privilegiato, in quanto al di fuori dei vincoli - leggi censura - che limitavano fortemente l'attività della maggior parte delle imprese consimili, specie di quelle che operavano in terra francese. Con la Société typographique de Neuchâtel i librai italiani stabilirono perciò presto tutta una serie di contratti, di cui sono rimaste ampie tracce negli Archivi della Société, che si sono fortunatamente conservati, e dai quali Stefania Valeri ha tratto la maggior parte dei documenti sui quali ha svolto la sua indagine. Un'indagine che le ha consentito non solo di ricostruire i rapporti che i diversi librai italiani instaurarono con la Société nei venti anni della sua attività, ma anche gli elenchi delle opere più richieste; quindi dei gusti $o$ delle tendenze dei lettori italiani, almeno di quelli che a questo importante canale si rivolsero. 
2 I risultati ai quali l'indagine svolta da Stefania Valeri è pervenuta sono interessanti per più di un verso. Se da un lato essi dimostrano il ruolo svolto da questa Casa editrice e da questa Agenzia libraria nella diffusione in territorio italiano di alcune delle opere più note o audaci della filosofia illuministica - ciò che l'A. dimostra bene attraverso il caso del barone d'Holbach - dall'altro essi confermano anche ciò che altre indagini - come quella da noi condotta tempo fa sui libri arrivati alle dogane veneziane - avevano lasciato intravvedere: e cioè che l'attenzione dei lettori italiani non si limitava, o si concentrava, solo sulle opere dei philosophes o degli autori che noi oggi consideriamo fondamentali, come Montesquieu, Voltaire o Rousseau. Se l'attenzione per i philosophes o per gli autori appena ricordati era forte, altrettanto forte fu l'interesse che i lettori italiani mostrarono per altri settori della cultura francese: ad esempio la letteratura per l'infanzia, a causa dell'attenzione sempre maggiore ai problemi legati all'educazione dei bambini; oppure la cosiddetta letteratura di viaggio: quello autentico, che metteva il lettore in relazione con 1'«altro», ma anche quello immaginario, destinato a soddisfare sia la sua fantasia che la sua riflessione filosofica. L'attenzione maggiore andava però a quella che con parola moderna potremmo chiamare la «narrativa». Anche qui i documenti conservati negli Archivi della Société typographique confermano le indicazioni provenienti da altre fonti: vale a dire che gli autori più richiesti non erano quelli che ora noi consideriamo più importanti, bensì autori caduti spesso nel dimenticatoio, ma che all'epoca svolsero un ruolo, non solo culturale ma anche letterario, tutto, o quasi da riscoprire. Il caso più emblematico è rappresentato da quel Baculard d'Arnaud di cui oggi pochi conoscono il nome, ma le cui opere, a partire dagli anni Settanta del Settecento, non solo furono autentici best sellers, ma influenzarono, assai più profondamente di quanto non fecero opere ora assai più famose, i gusti $\mathrm{e} i$ generi letterari dell'intera Europa ben oltre l'attività della Société typographique e la stessa Rivoluzione del 1789.

3 L'indagine di Stefania Valeri offre informazioni e spunti di riflessione che difficilmente potranno eludere non solo coloro che vorranno ricostruire la storia della cultura italiana nella seconda parte del Settecento, ma anche coloro che si accingeranno a ricostruire di quell'epoca una storia letteraria nel senso più tipico e completo del termine. Completa il volume un CD nel quale l'A. ha raccolto non solo le trascrizioni di tutte le commissioni ricevute dalla Société typographique de Neuchâtel da parte italiana, unitamente agli elenchi delle opere che la stamperia inviò di sua iniziativa ai corrispondenti della penisola, ma anche le lettere più significative che questi ultimi inviarono alla Société e le risposte che ne ricevettero. 